\title{
Cardiac Arrest in a Morbidly Obese Patient with Undiagnosed Cardiomyopathy after Spinal Anaesthesia for Caesarean Section - a Case Report
}

\author{
Frederick Ebegue Amadasun \\ Department of Anaesthesiology, University of Benin Teaching Hospital \\ P.M.B. 1111, Benin City, Nigeria \\ Tel: 23-480-3375-0705_E-mail: amadasun1001@yahoo.com
}

Received: May 13, 2011 Accepted: June 9, 2011 doi:10.5539/gjhs.v3n2p191

\begin{abstract}
A 34-year old gravida 5, para $1^{+3}$ (none alive), presented with an 8-hour history of labour at 36 weeks gestation. On examination, she was grossly obese (BMI 43), had a pulse rate of $92 \mathrm{bpm}$, blood pressure of 100/70 mmHg and bilateral pedal oedema. She had a singleton fetus, lying transverse. Emergency Caesarean section was planned. In the operating theatre, she had spinal (subarachnoid) blockade with a 25-G Whitacre spinal needle and $2.2 \mathrm{ml}$ of $0.5 \%$ hyperbaric bupivacaine. Shortly thereafter, she complained of a progressively worsening respiratory difficulty, for which she was intubated and ventilated. Large amounts of blood -stained frothy fluid poured out of the pharynx at laryngoscopy, and from the endotrachial tube after intubation. She had cardiac arrest, and all resuscitative efforts failed.
\end{abstract}

Keywords: Spinal anesthesia, Caesarean section, Cardiac arrest

\section{Introduction}

Intraoperative cardiac arrests, though not common occurrences, do occasionally happen. While earlier North American studies put the incidence at 1 in 1600 adults undergoing anesthesia, (Girardi \& Bane, 1995), more recent studies from the region quote incidence of 1.1 per 10,000 (An et al., 2004). The incidences quoted, which are usually for non-cardiac surgical procedures, seem to reflect regional trends. European figures, which are put at 1-2 per 10,000 (White, 2003), are similar to the American rates. A Japanese study recorded a rate of $0.136 \%$, which is 13.6 per 10,000 (Osamu et al., 1999). Local studies in Nigeria even quote higher rates (Desalu et al., 2006). For example, Desalu and Kushimo (2007) reported an incidence of 6 per 1,000 (i.e. 60 per 10,000), in a one-year prospective study at the University of Lagos Teaching Hospital in Nigeria. In a 5-year retrospective study at the University College Hospital, Ibadan, Nigeria, Sanusi et al. (2001) reported an incidence of 55 per 10,000 operations.

Quite often, the resuscitative efforts by anesthetists reestablish spontaneous circulation and save the patient's life. In one study, successful intraoperative resuscitation occurred in about 60\% of patients (Hawkins et al., 1997). This contrasts markedly with out-of-theatre arrests where survival rates are put at $24 \%$ and $22 \%$ for in-hospital and out-of-hospital arrests respectively (Hawkins et al., 1997). The above quoted figures are not discriminatory of the type of anesthesia (general or regional) used. Comparative figures of cardiac arrests and survival rates between general and regional anesthesia, suggests the latter to be much safer, especially in obstetric anesthesia practice (Hawkins et al., 1997). Indeed, North American studies put the risk of death from complications of general anesthesia to be 16.7 higher than that of regional anesthesia (Hawkins et al., 1997).

Spinal anesthesia (subarachnoid block) is increasingly being used in many parts of the world for Caesarean section. It is recommended for both its efficiency and safety (Hawkins et al., 1997). Cardiac arrest after subarachnoid blockade has been reported in apparently healthy patients (Mackay et al., 1989). The results of resuscitative efforts are usually functions of many variables. These include the preoperative physical status of the patients, the type of premedication given (especially opioids and sedatives), the height of the neural blockade and the experience of the anesthetist. When intraoperative cardiac arrest occurs in an apparently healthy patient, there are good reasons to be optimistic of resuscitative efforts. When resuscitation fails to reestablish spontaneous circulation, concerted efforts are made to unravel the reasons. Such was the case with this morbidly 
obese patient (BMI 43), who had subarachnoid neural blockade for Caesarean section. She developed a progressively worsening respiratory difficulty on the operating table, culminating in a decision to intubate and ventilate her. On laryngoscopy after induction of anesthesia, copious fluid poured out of the pharynx. She had cardiac arrest after intubation, and all resuscitative efforts failed. The case is presented and discussed, with a review of the literature.

\section{Case presentation}

The patient was a 34-year old gravida 5 para $\mathbf{1}^{+3}$ (none alive), who presented with an 8-hour history of labor at 36 weeks gestation. She had a previous history of intrauterine fetal death at 41 weeks gestation, 4 years prior to presentation. She booked her index pregnancy at 16 weeks, and had 9 uneventful antenatal visits. Examination revealed a morbidly obese woman (weight $102 \mathrm{~kg}$, height $1.54 \mathrm{~m}$, BMI 43 ). The pulse rate was 92 beats per minute (bpm) and the blood pressure was $110 / 70 \mathrm{mmHg}$. She had bilateral pitting pedal edema. . She had a singleton fetus, lying transverse and with a fetal heart rate of $140 \mathrm{bpm}$. The cervix was $1 \mathrm{~cm}$ dilated, 30\% effaced. There was obvious liquor drainage. Emergency lower segment Caesarean section was planned. The patient's preoperative packed cell volume (PCV) was $30 \%$, and the urinalysis was normal. The airway was graded as Malampatti 3, and the physical fitness status was graded as ASA 2E.

In the operating theatre, intravenous ranitidine, $50 \mathrm{mg}$ and metoclopramide, $10 \mathrm{mg}$ were given. The patient was preloaded with $1200 \mathrm{ml}$. of $0.9 \%$ normal saline given over 30 minutes. Subarachnoid blockade was done under aseptic technique. The patient was placed in the sitting position, and a 25-guage Whitacre spinal needle was used to administer $2.2 \mathrm{ml}$ of $0.5 \%$ hyperbaric bupivacaine in the subarachnoid space. The level of sensory blockade was up to the T6 dermatome, using pin prick test. The blood pressure dropped to 90/50 mmHg after 10 minutes, and the heart rate was $90 \mathrm{bpm}$. The intravenous fluid infusion rate was increased, and the patient was given incremental doses of ephedrine. She had a total of $15 \mathrm{mg}$ in 3 divided doses over 15 minutes. The blood pressure rose to 130/70 $\mathrm{mmHg}$, with a pulse rate of $92 \mathrm{bpm}$. Thereafter, the patient started complaining of difficult breathing. Oxygen was administered by face mask. The dyspnea persisted and progressively worsened. A decision was taken to intubate and ventilate the patient.

Adopting rapid sequence technique with cricoid pressure, $400 \mathrm{mg}$ of thiopentone sodium and $100 \mathrm{mg}$ of suxamethonium chloride were given intravenously in sequence. On laryngoscopy, large volume of frothy fluid poured out of the pharynx. This was suctioned, and the trachea was eventually intubated after two attempts. The endotracheal tube was connected to a Magill's breathing system and artificial ventilation instituted. Ventilation was a bit difficult, as airway resistance was rather high. Meanwhile, copious frothy fluid continuously poured out of the endotracheal tube, despite vigorous efforts at suctioning. The patient had a cardiac arrest about 5 minutes after induction of anaesthesia and intubation. External cardiac massage was initiated, while ventilation continued. The patient was given intravenous adrenaline, $1 \mathrm{mg}$. This was repeated intermittently throughout the cardiopulmonary resuscitation (CPR) period, to a total dose of $5 \mathrm{mg}$. Spontaneous circulation could not be reestablished, and CPR was abandoned after 45 minutes.

Postmortem examination of the patient revealed cardiomyopathy that was undiagnosed premortem.

\section{Discussion}

The sequence of events that culminated in the eventual cardiac arrest in this patient, started with respiratory difficulty. The patient continuously complained of a progressively worsening breathing difficulty. The attending anesthetist ascribed this to an ascending respiratory muscle paralysis, probably from high neural blockade, hence the decision to intubate and ventilate the patient. The patient had a sensory neural blockade to T6 level. It is said that spinal anesthesia sensory levels to T4 segment do not lead to hypoventilation, and that some are actually associated with mild hyperventilation (Pollard, 2001). Whereas this may be so in the normal patient, the situation may be different in the morbidly obese patient. Ventilatory efficiency and respiratory reserve are much reduced in the morbidly obese (Adams \& Murphy, 2000); hence some workers advise that caution should be exercised with regional anesthesia, especially when the block extends beyond the umbilicus (T10). Paralysis of the intercostals muscles, in combination with assumption of the supine position may provoke respiratory failure (Adams \& Murphy, 2000; Biring et al., 1999). It has been shown that assumption of the supine position can be fatal in some morbidly obese patients if their cardiac reserve is limited (Oberg \& Poulsen, 1996). This may have been the case with this patient, especially with the postmortem finding of a cardiomyopathy.

The patient had a florid pulmonary edema. This may have contributed to the failure of CPR, as pulmonary gaseous exchange may have been impaired. The edema is probably negative pressure pulmonary edema. It occasionally arises in situations of inspiration against an obstructed airway and altered sensorium. In clinical anesthesia practice, triggering events include laryngospasm and endotracheal tube obstruction during emergence 
from anesthesia. In the case of this patient, altered consciousness from respiratory depression may have caused the tongue to fall back and block the glottis. Inspiratory effort against a closed glottis could induce negative pressure pulmonary edema. In the 1994-1996 Confidential Enquiry into Maternal Deaths in the UK (1998), the only death directly attributed to anesthesia, was in a case of high spinal block leading to respiratory depression, florid pulmonary edema and cardiac arrest, in a patient for elective Caesarean section. Resuscitation was unsuccessful. This patient's case appears very similar.

Postmortem examination of the patient revealed a cardiomyopathy that was not diagnosed during antenatal care or the perioperative period. This could be peripartum cardiomyopathy. It has been defined clinically "as the onset of cardiac failure with no identifiable cause in the last month of pregnancy or within 5 months after delivery, in the absence of heart disease before the last month of pregnancy" (Ray et al., 2004). It is associated with older maternal age, greater parity, black race and multiple gestations (Ray et al., 2004). Many of these features were present in this patient. The diagnosis of peripartum cardiomyopathy presents a challenge, because many normal women in the last month of a normal pregnancy, experience dyspnea, fatigue and pedal edema; symptoms identical to early congestive cardiac failure. The patient had bilateral pedal edema. It is possible that the progressive respiratory difficulty she had on the operating table was orthopnea of congestive cardiac failure. This may also explain the pulmonary edema and failure of resuscitative efforts.. These factors may have acted on their own, or with other factors earlier discussed.

If cardiomyopathy had been diagnosed preoperatively, it may not have affected the anaesthetic technique, as both general and regional anaesthesia could be used (Ray et al., 2004). The principle of anaesthetic management of a cardiac patient for non-cardiac surgery would apply. Experts actually advise that the mother's symptoms should be stabilized preoperatively by the cardiologist and obstetric physician, in consultation with the anesthetic staff (Ray et al., 2004). This patient was not availed this opportunity, as the cardiomyopathy was undiagnosed preoperatively. One way of forestalling scenarios like this, is a high index of suspicion and a low threshold of echocardiography in patients like this (Ray et al., 2004). Diagnosis rests on the echocardiographic identification of new left ventricular systolic dysfunction during a limited period around parturition, when other causes of cardiomyopathy have been excluded (Ray et al., 2004).

Following cardiac arrest in the patient, 45 minutes of cardiopulmonary resuscitation was unsuccessful, and was thus abandoned. CPR in pregnancy is difficult. The gravid uterus may make external cardiac massage less effective in the supine position, due to aortocaval compression. Left uterine displacement is recommended. However, in a pregnant patient in the third trimester, CPR is more difficult to perform in the wedged semi-lateral position. The American Society of Anesthesiology Task Force on Obstetrical Anesthesia Guidelines (1992) recommends that "if cardiac arrest occurs during labour and delivery, standard resuscitative measures and procedures, including left uterine displacement, should be undertaken". The American Heart Association Guidelines (1992) went further to say that in cases of cardiac arrest in pregnancy, "several authors now recommend that the decision to perform a perimortem Caesarean section should be made rapidly, with delivery affected within 4 to 5 minutes of the arrest”. The obstetricians did not perform a perimortem Caesarean section for the patient. This may have had salutary effects on resuscitative efforts. Uterine intravascular blood would be reinfused into the general circulation on uterine contraction, and aortocaval compression would be relieved. These would increase venous return, cardiac output and tissue perfusion. The chances of establishing spontaneous circulation would have been improved.

CPR was given up after 45 minutes of unsuccessful efforts. A decision to withhold or give up CPR is a contentious ethical issue. Mohr and Kettler (1997) opined that decisions by physicians to withhold or terminate resuscitation based on a medical judgment of futility might be justified. According to the American Heart Association Guidelines (1992), futility could be claimed in patients where appropriate resuscitative efforts have been attempted without restoration of circulation. Such was the case with this patient.

\section{Conclusion}

It may be rational to suggest that cardiac arrest in this patient may have resulted from high neural blockade of the spinal anesthesia. The respiratory depression / altered sensorium arising therefrom, may have caused a negative pressure pulmonary edema. However, the clinical scenario could be sequel to the undiagnosed cardiomyopathy. Maybe the preoperative observation of bilateral pedal edema should have raised the index of suspicion to further investigate the cardiovascular system of the patient, especially preoperative echocardiography. 


\section{References}

Adams, J. P. \& Murphy, P. G. (2000). Obesity in anaesthesia and intensive care. Br J Anaesth, 85, 91-108. http://dx.doi.org/10.1093/bja/85.1.91

American Heart Association, Guidelines for cardiopulmonary resuscitation and emergency cardiac care. (1992). JAMA, 268, 2171-2302. http://dx.doi.org/10.1001/jama.268.16.2171

An, J., Zhang, L., Sullivan, E. A., \& Williams, J. P. (2004). Intraoperative cardiac arrest during anaesthesia: A thirteen-year study in a major university hospital in the United States. Anesthesiology, 101, A1295.

Biring, M. S., Lewis, M. I., Liu, J. T., \& Mohsenifar, Z. (1999). Pulmonary physiological changes of morbid obesity. Am J Med Sci, 318, 293-297. http://dx.doi.org/10.1097/00000441-199911000-00002

Department of Health Welsh Office, Scottish Office Department of Health, Department of Health and Social Services Northern Ireland. (1998). Report on Confidential Enquiries Into Maternal Deaths in the United Kingdom 1994-1996. London, HMS.

Desalu, I. \& Kushimo, O. T. (2007). An audit of perioperative cardiac arrest at Lagos University Teaching Hospital. Niger J Clin Pract, 10, 188-93. http://dx.doi.org/10.1016/j.resuscitation.2005.10.012

Desalu, I., Kushimo, O. T., \& Akinlaja, O. (2006). Adherence to CPR guidelines during perioperative cardiac arrest in a developing country. Resuscitation, 69, 517-20.

Girardi, L. N. \& Bane, P. S. (1995). Improved survival after intraoperative cardiac arrest in non-cadiac surgical patients. Arch Surg, 130, 15-18.

Hawkins, J. L., Koonin, L. M., Palmer, S. K., \& Gibbs, C. P. (1997). Anesthesia-related deaths during obstetric delivery in the United States, 1979-1990. Anesthesiology, 86, 277-84. http://dx.doi.org/10.1097/00000542-199702000-00002

Mackey, D. C., Carpenter, R. L., Thompson, G. E., Brown, D. L. \& Bodily, M. N. (1989). Bradycardia and asystole during spinal anaesthesia: a report of three cases without morbidity. Anesthesiology, 70, 866-7. http://dx.doi.org/10.1097/00000542-198905000-00026

Mohr, M. \& Kettler, D. (1997). Ethical aspects of resuscitation. Br J Anaesth, 79, 2539.

Oberg, B. \& Poulsen, T. D. (1996). Obesity: an anaesthetic challenge. Acta Anaesthesiol Scand, 40, 191-200. http://dx.doi.org/10.1111/j.1399-6576.1996.tb04419.x

Osamu, T., Nagano, K., Okada, Y., Sakamoto, M., Sugihara, H., \& Yamanaka, I. (1999). Intraoperative cardiac arrest associated with anaesthesia and surgery. A retrospective study over 13 years period. Hiroshima J Anesth, 113-6.

Pollard, J. B. (2001). Cardiac arrest during spinal anaesthesia: common mechanisms and strategies for prevention. Anesth Analg, 92, 252-56. http://dx.doi.org/10.1097/00000539-200101000-00050

Practice Guidelines for Obstetrical Anesthesia: a Report by the American Society of Anesthesiologists Task Force on Obstetrical Anesthesia. (1999). Anesthesiology, 90, 600-11. http://dx.doi.org/10.1097/00000542-199902000-00035

Ray, P., Murphy, G. J., \& Shutt, L. E. (2004). Recognition and management of maternal cardiac disease in pregnancy. Br J Anaesth, 93, 428-39. http://dx.doi.org/10.1093/bja/aeh194

Sanusi, A. A., Soyannwo, A., \& Amanor-Boadu, S. D. (2001). Intraoperative cardiac arrests. West Afr J Med, 20, 192-5.

White, S. M. (2003). Death on the table. Anaesthesia, 58, 515-8. http://dx.doi.org/10.1046/j.1365-2044.2003.03241.x 